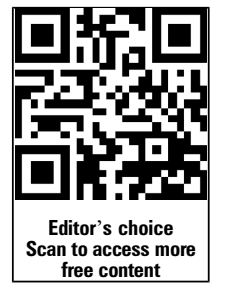

- Additional material is published online only. To view please visit the journal online (http://dx.doi.org/10.1136/ sextrans-2013-051472).

Department of Epidemiology and Biostatistics, The George Washington University, Washington, District of Columbia, USA

\section{Correspondence to} Dr Sara Nelson Glick, The George Washington University, 950 New Hampshire Ave NW, Suite 500, Washington, DC 20052, USA; snglick@gwu.edu

Received 6 December 2013 Revised 15 March 2014 Accepted 23 March 2014 Published Online First 10 April 2014

\title{
The use of web-based diaries in sexual risk behaviour research: a systematic review
}

\author{
Carolyn Stalgaitis, Sara Nelson Glick
}

\section{ABSTRACT}

Background An increasing number of studies have used the diary method, which provides quantitative event-level data about sexual encounters. Diaries are an attractive tool for sexual behaviour research, yet little is known about the range of uses, methodological issues and best practices associated with this technology. Objectives To conduct a systematic review of the literature regarding the use of web-based diaries in sexual risk behaviour studies.

Design Systematic review.

Data sources Five bibliographical databases, supplemented by references from previous reviews. Methods Eligible studies were published in English before August 2013, used the internet to transmit data from collection device to study staff, and measured behaviours affecting HIV or sexually transmitted infection transmission risk. The primary author conducted an initial screen to eliminate irrelevant articles. Both authors conducted full-text reviews to determine final articles. We abstracted data on diary methodology, validity and reactivity (behaviour change caused by diary completion). Results Twenty-three articles representing 15 studies were identified. Most diaries were collected daily for 1 month via websites, and completion was generally high (>80\%). Compensation varied by study and was not associated with completion. Studies comparing diary with retrospective survey data demonstrated evidence of over-reporting on retrospective tools, except for the least frequent behaviours. Most studies that assessed reactivity as a result of diary completion demonstrated some change in behaviour associated with frequent monitoring.

Conclusions Web-based diaries are an effective means of studying sexual risk behaviour. More uniform reporting and further research on the extent of reactivity are needed.

\section{INTRODUCTION}

One of the greatest methodological challenges in HIV and sexually transmitted infections (STIs) research is obtaining valid measures of sexual behaviour. Increasingly, sexual behaviour studies use the diary method, which provides quantitative event-level data about sexual encounters. Although potentially burdensome to participants due to the time and effort required to complete diaries, their frequent nature confers advantages over methods such as retrospective (eg, 30-day) surveys, including improved recall. ${ }^{1}$ Diaries typically collect daily data such as number of partners, ${ }^{2} \operatorname{mood}^{3}$ or STI symptoms ${ }^{4}$ which may be more precise than aggregate measures collected in retrospective surveys. ${ }^{1} 56$ Event-level data may also allow for more accurate identification of predictors of risky behaviour and HIV/STI transmission. ${ }^{6}$

These advantages make diaries an attractive tool for sexual behaviour research. Historically, paper diaries were most common, despite several shortcomings. Compliance with the diary schedule is difficult to confirm, and participants may hoard diaries and complete multiple entries at once, increasing the potential for measurement error. ${ }^{7-9}$ Participants in paper diary studies often must carry physical diaries with them, and may forget to complete them without frequent reminders from study staff. ${ }^{110}$ Additionally, paper diaries require staff to physically enter responses into a database, leading to increased staff burden and a high potential for data entry errors given the volume of responses collected in most diary studies. ${ }^{111}$

In response to technological advances and the limitations of paper diaries, researchers have increasingly employed electronic diaries. Electronic diaries can be collected by email, website, personal digital assistant (PDA), phone or other means of electronic data recording. This allows diaries to be time-stamped, and may be more convenient for participants. ${ }^{1}{ }^{10}{ }^{12}$ Electronic diaries can implement skip patterns to reduce participant burden, identify incomplete or out-of-range responses in real time and reduce data entry errors. ${ }^{1} 1012$ The electronic format may also increase privacy. ${ }^{1} 12$ This is an important consideration for HIV/STI diary research given that diaries may collect partners' initials or names, thereby increasing risk of confidentiality breach.

Electronic diaries, especially formats that permit remote data collection, possess enormous potential for sexual behaviour research. However, little is known about the range of uses, methodological issues such as reactivity (behaviour changes that result from study participation) and best practices associated with this technology. To inform the use of diaries in future studies, we conducted a systematic review of the published literature on web-based diaries used for sexual risk behaviour research. Specifically, we examined the following characteristics of these studies: objectives; study populations; diary collection methods and frequency; variables measured; compensation; approaches to missing data; diary completion rates; participant acceptability and privacy; diary and survey data validity; and evidence of reactivity or behaviour change as a result of diary completion.

\section{METHODS}

\section{Search strategy and selection criteria}

A systematic review of the literature was conducted in August 2013 to identify sexual risk behaviour 
studies that used web-based diaries. We searched five databases (PubMed; EMBASE; CINAHL; MEDLINE; Cochrane Library) to identify relevant articles using the following search terms: ('diary' OR 'diaries') AND ('sexual health' OR 'sexually transmitted' OR 'STI' OR 'STD' OR 'sexual behaviour' OR 'HIV' OR 'AIDS'). Studies published in August 2013 or earlier were eligible for inclusion.

Studies meeting the following criteria were included in our review: (1) used web-based diaries; (2) measured sexual risk behaviours; (3) published as a peer-reviewed article by August 2013; (4) English language. We excluded poster or presentation abstracts, case reports, letters to the editor, opinion articles and reviews. Studies could be of any design, but the diary methodology inherently limited results to prospective studies.

We defined web-based diaries as those that used the internet to transmit data from participants to study staff. This included website-based and email-based diaries, along with cell phone or PDA diaries that transmitted data over the internet. Studies that transferred data differently such as through the physical exchange of memory cards were excluded.

To identify articles most relevant to HIV/STI research, we focused on studies that measured HIV/STI incidence and/or examined risk factors for transmission. We included studies that examined condom use, whether or not they explicitly studied incidence, because of the importance of condoms in preventing transmission. Studies of sexual pleasure, contraception other than condoms and sexual dysfunction were excluded.

\section{Study selection and data extraction}

From our database search, we generated a list of relevant citations and identified additional citations from references. The primary author scanned articles to exclude citations obviously irrelevant to our review such as studies of erectile dysfunction, sexual pleasure or contraception other than condoms. Both authors reviewed the remaining articles, abstracted data and integrated results to determine the final set of articles. Inconsistencies were resolved by discussion between authors. To the extent possible, we collected the following information from each study: objectives; diary medium, frequency and collection period; study population; sample size; variables measured; participant acceptability and privacy; compensation; and how missing data were handled. Information was also abstracted on diary completion rates, validity of diary data and reactivity. We included validity data because diaries are considered the gold standard for sexual behaviour research, due to the inability of researchers to directly observe sexual behaviour and the lack of confirmatory biological measures. ${ }^{13-15}$ As a result, diaries are compared with less resource-intensive methods, such as retrospective surveys, to assess the validity of alternative methods. We also examined reactivity, the phenomenon whereby recording a behaviour causes subjects to change that behaviour, because its occurrence may bias observational diary studies. ${ }^{1}{ }^{16}$ We did not conduct a standardised bias or quality assessment as we were interested in studies' methods rather than conclusions. Instead, the data we collected-including completion rates, validity and reactivity - were indicators of study quality and potential biases that assisted us in identifying optimal methodological practices.

\section{RESULTS}

Figure 1 presents a flowchart of the screening process. The initial database search yielded 1440 unique records. An additional 245 citations did not include the specific search terms but were identified from references in reviewed articles. The primary author deemed 358 citations potentially relevant based on their titles and reviewed their abstracts to exclude ineligible studies. This yielded 35 articles for full-text review by both authors. Upon closer examination, we excluded 2 articles that used PDAs but did not transmit data using the internet ${ }^{17} 18$ and 10 articles that did not measure sexual risk behaviours as per our eligibility criteria. ${ }^{19-28}$ This left 23 articles representing 15 studies that used web-based diaries to examine sexual risk behaviour. $^{2} 329-49$

\section{Objectives of studies using web-based diaries}

Article objectives ranged from identification of HIV/STI risk factors to methodological research. Unprotected sex was a common focus; four articles examined a range of predictors and correlates of condom use, ${ }^{35363948}$ while others focused on specific risk factors such as substance use $(n=4)^{30} \quad 384043$ or $\operatorname{mood}(n=2) .{ }^{34}{ }^{41}$ Four assessed rates and predictors of human papillomavirus infection in college students. ${ }^{29} 314549$ Others examined racial differences in risk behaviours of men who have sex with men (MSM), ${ }^{44}$ online partnering among $\mathrm{MSM}^{42}$ and condom breakage/slippage. ${ }^{46}$

Several studies focused on methodological issues, including the feasibility of using diaries with specific populations ${ }^{33}$ and high-frequency diary schedules. ${ }^{3}$ One compared web-based diaries with text message and paper diaries, ${ }^{2}$ while another compared diary schedules. ${ }^{33}$ Four assessed the validity of retrospective recall surveys. ${ }^{2} 323337$

\section{Methodological characteristics}

Table 1 presents descriptive characteristics of the reviewed studies (see online supplementary table S4). The most common diary collection method was a website $(n=13)^{2} 29-3133-49$ and the most common submission frequency was daily $(n=8) . .^{32} 34-424647$ One study, which used cell phones to collect data, administered diaries thrice daily. ${ }^{3}$ Seven studies collected diaries for 1 month. ${ }^{32}$ 34-42 46

The most frequently studied populations were MSM $(\mathrm{n}=7)^{30} \quad 33-35 \quad 37 \quad 40-44 \quad 48$ and university students $(\mathrm{n}=5) .{ }^{29} 31323839454749$ Sample sizes ranged from $3877^{35}$ to $37^{32}$; seven studies had fewer than 100 subjects. 29 32-34 374749

We attempted to enumerate the frequency with which diaries measured specific variables based on information provided in each manuscript. The most common measures were condom use $(n=13)^{2} 293032-44-46-49$ and partner type $(n=12) .^{2} 29-3133-464849$ Studies assessed partner type with varying specificity, including new versus repeat, $22931333740-4549$ casual versus main 2303435383948 or even further detail (ie, girlfriend, spouse, etc). ${ }^{36} 46$ Diaries were also used to measure the type of sexual activity that occurred (oral, vaginal or anal sex), ${ }^{3}$ 29-37 40-46 4849 partner-specific rather than $\begin{array}{llllllll}\text { aggregate behaviours }^{2} & 3 & 29 & 31-34 & 37 & 40-42 & 45 & 49\end{array}$ and substance use. $^{3} 30343638-444648$

Compensation for participation varied. Three studies paid participants per diary entry ${ }^{3} 293349$ and three paid per entry with a bonus for high completion. ${ }^{2} 34$ 40-42 Average compensation per diary day was $\$ 1.18$ (range: $\$ 0.14 \$-3.00$ ). The cellphone-based study, in addition to financial compensation, provided participants with free domestic phone calls, text messages and phone-based internet access during the study, with the option to retain the phone at study completion.

Missing data can introduce bias into a study if appropriate analytical steps are not taken. ${ }^{50}$ Among studies that reported how they treated missing data, three excluded participants with missing data, ${ }^{3}$ 40-44 three used modelling techniques that accounted for missing data ${ }^{29} 343549$ and one used imputation. $^{33}$ Missing data are especially relevant for studies 
Figure 1 Search and selection flow chart for a systematic review of web-based diaries in sexual risk behaviour research.

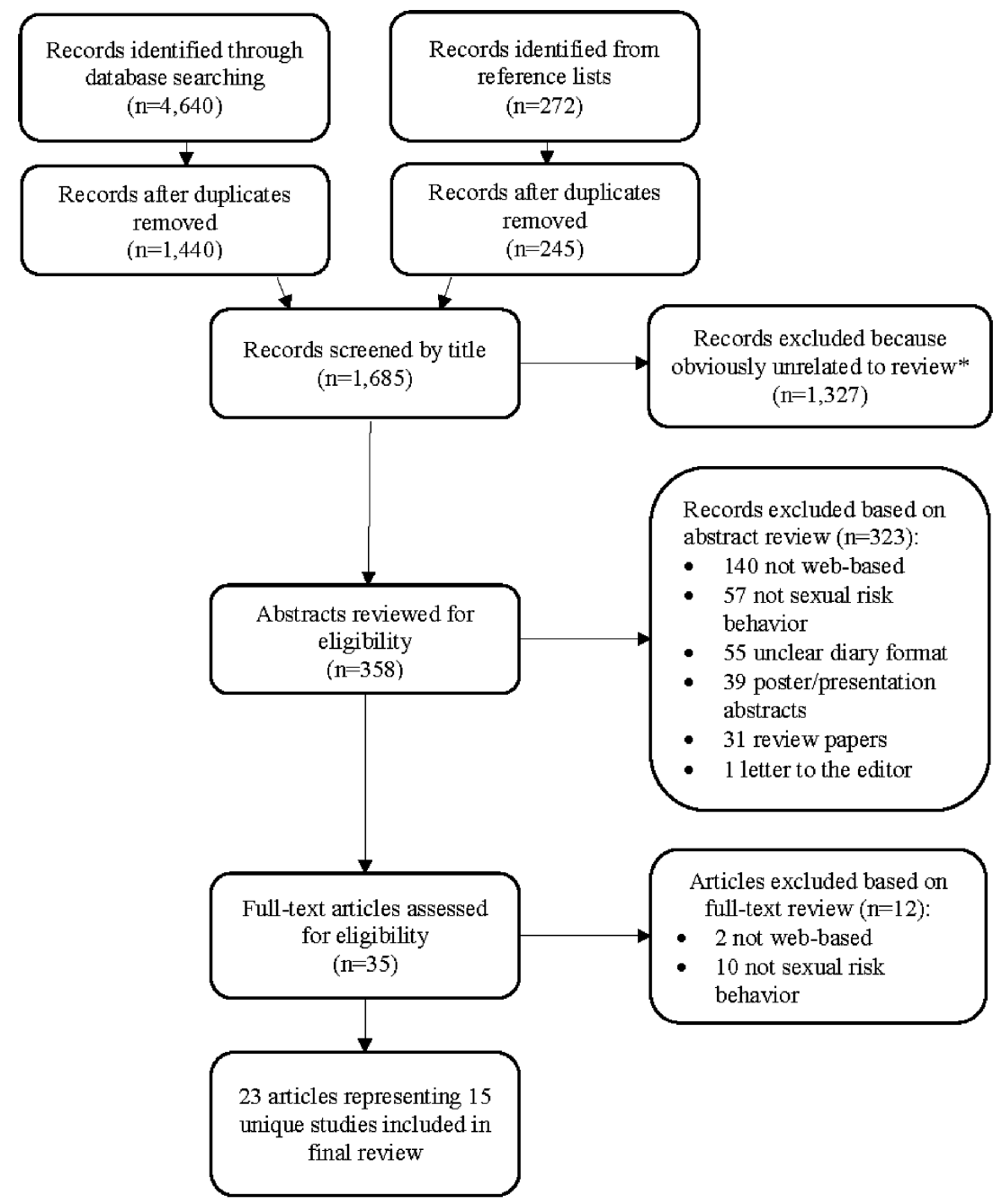

*Includes studies on erectile dysfunction, sexual pleasure, and contraception other than condoms or studies that did not use a diary methodology

comparing diary and recall data; only one of the four studies that did so addressed data missingness, using imputation. ${ }^{33}$

\section{Diary completion rates}

No single measure of diary completion was reported by all studies (table 2). Regardless of the measures provided, most studies reported relatively high completion. Nine reported that $>80 \%$ of all diaries were submitted. ${ }^{2} 3 \quad 2931-33 \quad 3740-4549$ Four separately reported the proportion of diaries submitted on time; two reported on-time rates $>90 \% .^{32} 47$ To enable comparisons between studies, we divided the mean or median number of completed diaries by the number expected per subject to obtain a proportion. Four studies reporting means ${ }^{3} \quad 30 \quad 40-42 \quad 47 \quad 48$ and four reporting medians $^{2} 3303448$ had completion rates $>80 \%$. In a 12-month study of young MSM, Glick et al noted a substantial decline in completion after 6 months, ${ }^{33}$ however studies of a similar length in heterosexual populations did not report comparable declines. ${ }^{29} 314549$

We attempted to identify diary characteristics associated with high completion. For the studies in which appropriate data were available $(n=9)$, we plotted the overall completion rate by compensation per diary day and found almost no association $\left(\mathrm{R}^{2}=0.0047\right)$ (see online supplementary figure $\mathrm{S} 2$ ). We also compared completion rates by diary frequency and length of diary collection period, and found no significant differences.

\section{Participant acceptability and privacy}

Despite concerns about participant burden, ${ }^{1}$ diaries were wellreceived. In three studies reporting acceptability, participants found electronic diaries to be convenient and enjoyed participating. $^{2} 337$ Two studies reported that participants felt the diaries sufficiently protected their privacy. 237

\section{Validity}

Four studies used diaries to assess the validity of retrospective survey data and examined over-reporting and under-reporting in these surveys (table 3). Garry et al compared diary data with results from a surprise survey 6 months to 12 months later. ${ }^{32}$ On the survey, subjects under-reported number of partners and over-reported frequency of oral and vaginal sex and condom use. No difference was found for anal sex, the least frequent behaviour.

Horvath et al found that MSM significantly over-reported receptive oral and anal sex on a retrospective survey. ${ }^{37}$ The proportion of participants who correctly reported number of sexual episodes and oral sex was low. Recall was most accurate for unprotected receptive anal sex. Higher diary reports of total sexual episodes, giving or receiving oral sex, and partner ejaculation during oral sex were associated with over-reporting on the survey. Greater frequency of unprotected insertive anal sex was associated with under-reporting. 
Table 1 Design and methods of sexual risk behavior studies using web-based diaries

\begin{tabular}{|c|c|c|c|c|c|c|c|c|}
\hline Study & Diary medium & $\begin{array}{l}\text { Diary submission } \\
\text { frequency }\end{array}$ & $\begin{array}{l}\text { Diary } \\
\text { collection } \\
\text { period }\end{array}$ & Population & $\begin{array}{l}\text { Sample } \\
\text { size }^{*}\end{array}$ & Measurest & Compensation & Missing data \\
\hline Baer et al, Winer et a l $^{29} 49$ & Website & Biweekly & Up to 3 years & $\begin{array}{l}\text { University } \\
\text { women }\end{array}$ & 82 & $\begin{array}{l}1,2,3,4,8 \\
15\end{array}$ & $\$ 2$ per diary, up to $\$ 4$ per month & $\begin{array}{l}\text { Accounted for in } \\
\text { model }\end{array}$ \\
\hline Wilson et al, Boone et al ${ }^{30} 48$ & Website & Weekly & 6 weeks & MSM & 158 & $\begin{array}{l}1,2,3,5,7 \\
9,10\end{array}$ & $\begin{array}{l}\text { Increased from } \$ 5 \text { to } \$ 15 \text { per diary over } \\
\text { course of study }\end{array}$ & Not reported \\
\hline Partridge et al, Edelstein et $a l^{3145}$ & Website & Biweekly & $\begin{array}{l}\text { Up to } 1 \frac{1}{2} \\
\text { years }\end{array}$ & $\begin{array}{l}\text { University } \\
\text { men }\end{array}$ & 240 & $2,3,4$ & Not reported & $\begin{array}{l}\text { Missingness } \\
\text { discussed, no } \\
\text { methods reported }\end{array}$ \\
\hline Garry et $a l^{32}$ & Email & Daily & 1 month & $\begin{array}{l}\text { University } \\
\text { students }\end{array}$ & 37 & $1,3,4$ & $\$ 50$ for study participation & Not reported \\
\hline Glick et $a \beta^{33}$ & Website & $\begin{array}{l}\text { Randomised to twice } \\
\text { weekly, weekly, biweekly, } \\
\text { or no diary }\end{array}$ & 12 months & MSM & 95 & $1,2,3,4$ & $\$ 1.50$ per week of diaries & Imputation \\
\hline Grov et a $\beta^{34}$ & Website & Daily & 1 month & MSM & 47 & $\begin{array}{l}1,2,3,4,5 \\
6,7\end{array}$ & $\begin{array}{l}\$ 1 \text { per diary, with } \$ 10 \text { bonus for completing } \\
\geq 28 \text { entries }\end{array}$ & $\begin{array}{l}\text { Accounted for in } \\
\text { model }\end{array}$ \\
\hline Hensel et al ${ }^{3}$ & Cell phone & Three times per day & 3 months & $\begin{array}{l}\text { STI clinic } \\
\text { population }\end{array}$ & 243 & $\begin{array}{l}3,4,5,6,8 \\
12,16\end{array}$ & $\begin{array}{l}\$ 1 \text { per diary, plus free domestic calls, text } \\
\text { messages and phone-based internet }\end{array}$ & $\begin{array}{l}\text { Excluded participants } \\
\text { with missing data }\end{array}$ \\
\hline Reece et al, Hensel et al ${ }^{36} 46$ & Website & Daily & 1 month & Men & 1875 & $\begin{array}{l}1,2,3,5,9 \\
11,12\end{array}$ & 12 condoms; incentives valued up to $\$ 50-70$ & $\begin{array}{l}\text { Missingness } \\
\text { discussed, no } \\
\text { methods reported }\end{array}$ \\
\hline Hensel et al ${ }^{35}$ & Website & Daily & 1 month & MSM & 3877 & $\begin{array}{l}1,2,3,6,9 \\
11,13\end{array}$ & Not reported & $\begin{array}{l}\text { Accounted for in } \\
\text { model }\end{array}$ \\
\hline Horvath et $a l^{37}$ & Website & Daily & 1 month & MSM & 45 & $1,2,3,4,8$ & $\$ 50$ for study participation & Not reported \\
\hline Kiene et al, Kiene et $a^{38} 39$ & Website & Daily & 1 month & $\begin{array}{l}\text { University } \\
\text { students }\end{array}$ & 116 & $1,2,5,6$ & $\begin{array}{l}\text { Unspecified financial incentive prorated by } \\
\text { diary completion; research credit }\end{array}$ & Not reported \\
\hline Lim et $a l^{2}$ & $\begin{array}{l}\text { Randomised to website, } \\
\text { text message, or paper } \\
\text { diary }\end{array}$ & Weekly & 3 months & Young adults & 72 & $1,2,4$ & $\begin{array}{l}\$ 2 \text { per paper/web or } \$ 3 \text { per text message } \\
\text { diary; } \$ 25 \text { music store voucher for completing } \\
\text { all diaries and follow-up survey }\end{array}$ & $\begin{array}{l}\text { Missingness } \\
\text { discussed, no } \\
\text { methods reported }\end{array}$ \\
\hline $\begin{array}{l}\text { Mustanski, Mustanski, } \\
\text { Mustanski }{ }^{40-42}\end{array}$ & Website & Daily & 1 month & MSM & 155 & $\begin{array}{l}1,2,3,4,5 \\
6,7,10\end{array}$ & $\begin{array}{l}\$ 1 \text { per diary, with } \$ 10 \text { bonus for completing } \\
\geq 28 \text { entries }\end{array}$ & $\begin{array}{l}\text { Excluded participants } \\
\text { with missing data }\end{array}$ \\
\hline $\begin{array}{l}\text { Newcomb, Newcomb and } \\
\text { Mustanski }{ }^{43} 44\end{array}$ & Website & Weekly & 3 months & MSM & 143 & $\begin{array}{l}1,2,3,5,7 \\
13\end{array}$ & $\$ 60$ prorated by diary completion & $\begin{array}{l}\text { Excluded participants } \\
\text { with missing data }\end{array}$ \\
\hline Strachman and Impett ${ }^{47}$ & Website & Daily & 2 weeks & $\begin{array}{l}\text { University } \\
\text { students }\end{array}$ & 75 & 1,14 & $\begin{array}{l}\text { Entry into lottery for } \$ 100 \text { for completing } \geq 11 \\
\text { diaries; research credit }\end{array}$ & Not reported \\
\hline
\end{tabular}

*For studies reported in multiple articles, the largest reported sample size is presented.

TMeasures: (1) condom use; (2) partner type; (3) type of sex; (4) partner-specific data; (5) substance use; (6) mood; (7) partner HIV status; (8) partner name or initials; (9) sexual event location; (10) method of meeting partner; (11) lubrication use; (12)

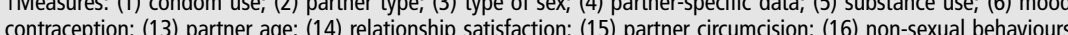


Table 2 Diary completion rates among sexual risk behavior studies using web-based diaries

\begin{tabular}{|c|c|c|c|c|}
\hline Study & $\begin{array}{l}\text { Proportion of diaries } \\
\text { submitted on time }\end{array}$ & $\begin{array}{l}\text { Total proportion of } \\
\text { diaries submitted }\end{array}$ & $\begin{array}{l}\text { Proportion of subjects who reached } \\
\text { specific completion level }\end{array}$ & $\begin{array}{l}\text { Mean/median number of } \\
\text { diaries completed per } \\
\text { subject }\end{array}$ \\
\hline Baer et al, Winer et al ${ }^{29} 49$ & - & $90.7 \%$ & - & - \\
\hline $\begin{array}{l}\text { Wilson et al, } \\
\text { Boone et } a l^{30} 48\end{array}$ & - & $78.0 \%$ & - & $\begin{array}{l}\text { Mean: } 5.2 / 6 \\
\text { Median: } 6 / 6\end{array}$ \\
\hline $\begin{array}{l}\text { Partridge et al, } \\
\text { Edelstein et } a l^{1145}\end{array}$ & - & $94.8 \%$ & - & - \\
\hline Garry et $a^{32}$ & $99.8 \%$ & $100.0 \%$ & $94.6 \%$ completed all diaries on time & - \\
\hline Glick et $a l^{33}$ & - & $81.6 \%$ & $\begin{array}{l}\text { Completed }>80.0 \% \text { of diaries: } 82.0 \% \text { in mo. } 1-3 \text {; } \\
72.0 \% \text { in mo. } 4-6 ; 57.1 \% \text { in mo. } 7-9 ; 55.6 \% \text { in mo. } 10-12\end{array}$ & - \\
\hline Grov et $a l^{34}$ & - & $75.2 \%$ & - & $\begin{array}{l}\text { Mean: } 22.5 / 30(S D=8.3) \\
\text { Median: } 26 / 30\end{array}$ \\
\hline Hensel et $a l^{\beta}$ & - & $89.7 \%$ & $82.3 \%$ completed $99.2 \%$ of diaries & $\begin{array}{l}\text { Mean: } 18.9 / 21 \text { per week } \\
\text { Median: } 20 / 21 \text { per week }\end{array}$ \\
\hline Reece et $a l$, Hensel et $a l^{3646}$ & - & $61.9 \%$ & - & - \\
\hline Hensel et $a l^{35}$ & - & - & $\begin{array}{l}25.0 \% \text { completed all diaries; } 30.0 \% \text { completed } 50.1-99.9 \% \text { of } \\
\text { diaries }\end{array}$ & Mean: $13 / 30(S D=10)$ \\
\hline Horvath et $a l^{37}$ & $72.0 \%$ & $99.7 \%$ & $97.8 \%$ completed all diaries & - \\
\hline Kiene et al, Kiene et al ${ }^{38} 39$ & - & $79.4 \%$ & - & Mean: 23.8/30 (SD=6.1) \\
\hline Lim et $a l^{2}$ & $62.6 \%$ & $99.3 \%$ & $98.5 \%$ completed at least one diary & Median: $13 / 13$ \\
\hline $\begin{array}{l}\text { Mustanski, Mustanski, } \\
\text { Mustanski }{ }^{40-42}\end{array}$ & - & $83.6 \%$ & $70.0 \%$ completed at least $20 / 30$ & Mean: $24.4 / 30(S D=9.9)$ \\
\hline $\begin{array}{l}\text { Newcomb, Newcomb and } \\
\text { Mustanski }{ }^{434}\end{array}$ & - & $83.7 \%$ & - & - \\
\hline Strachman and Impett ${ }^{47}$ & $93.8 \%$ & - & $90.0 \%$ completed all diaries on time & Mean: $13 / 14$ on time \\
\hline
\end{tabular}

Glick et al assessed survey validity in a sample of MSM. ${ }^{3}$ Concordance correlation coefficients and $\kappa$ statistics exceeded 0.80 for almost all sexual behaviours assessed, indicating considerable agreement between methods. ${ }^{33}$ Similarly, Lim et al randomised young adults to complete weekly diaries online, on paper or by text message, and compared results with a retrospective survey. $^{2}$ Correlation was highest for the proportion of regular versus casual partners (0.87), mean frequency of sex (0.76), mean frequency of using condoms $(0.76)$ and STI risk $(0.74){ }^{2}$

\section{Reactivity}

Five studies assessed reactivity (table 3), including one controlled study. Glick et al compared quarterly surveys from participants randomised to an active diary or control group. ${ }^{33}$ Compared with diary subjects, controls reported significantly greater increases over time in the occurrence of anal sex, frequency of anal and unprotected anal sex, and acquisition of new male partners. These behavioural differences may explain the significantly higher rate of incident HIV/STI diagnoses in control $(26.1 \%)$ than diary subjects $(4.8 \%, \mathrm{p}=0.01)$.

Four studies assessed reactivity by analysing intrapersonal temporal trends in behaviour, without comparing with a control. In their cellphone study, Hensel et al noted that diary submission rates declined significantly each week, demonstrating completion reactivity, and reports of vaginal sex declined significantly over time, demonstrating behavioural reactivity. ${ }^{3}$ Horvath et al examined trends in behaviour in a diary study of MSM and found that giving and receiving oral sex, insertive anal sex, and receptive unprotected anal sex decreased significantly over time. ${ }^{37}$ Two studies concluded that their data showed no evidence of reactivity. ${ }^{38} 394344$

\section{DISCUSSION}

Web-based diaries are increasingly popular for collecting detailed sexual behaviour data. To date, most studies have been small and not designed to assess methodological questions. There does not appear to be one single web-diary design that best measures sexual risk behaviour, and individual study needs should guide methodological decisions regarding diary frequency, medium and content. Nevertheless, our review identified interesting patterns and lessons learned across studies that implemented web-based diaries.

Diary completion rates in the reviewed studies were generally high. Nearly all studies provided compensation, but the amount of compensation was not associated with completion. While most collected data were based on daily behaviour, researchers succeeded using a variety of diary submission schedules. In one study that directly compared three submission schedules, the less frequent schedules had higher completion rates. ${ }^{33}$ Most diary studies lasted for 1 month, although some had success with more frequent (eg, thrice daily) or longer duration data collection. In a recent study of young MSM, the decline in completion rates over time may have resulted from higher frequency of sexual behaviour relative to other populations. This suggests that future studies should employ strategies to simplify data collection and encourage long-term participation. Inconsistent reporting of completion data and diary measures hindered our ability to further identify methods associated with improved completion. To enhance comparability, authors should at minimum report the total proportion of diaries received and should consider following the guidelines for reporting completion rates proposed by Stone and Shiffman, ${ }^{51}$ including reporting what constituted complete and on-time submissions.

Several studies used diaries to assess the validity of retrospective surveys. Condom use, partner type, frequency and type of 
Table 3 Validity and reactivity findings for studies using web-based diaries

\begin{tabular}{|c|c|}
\hline Study & Findings \\
\hline \multicolumn{2}{|l|}{ Validity* } \\
\hline Garry et $a l^{32}$ & $\begin{array}{l}\text { Compared daily diaries with surprise retrospective survey } 6-12 \text { months later } \\
\text { Under-reported number of partners }(p=0.02) \text { on survey } \\
\text { Over-reported frequency of any sex, vaginal sex and oral sex on survey (all } p<0.01) \\
\text { Over-reported condom use for vaginal }(p=0.02) \text { and oral sex }(p=0.06) \text { on survey } \\
\text { Vaginal sex was reported four times more often in retrospective survey than diaries } \\
\text { - Po significant differences in recall of anal sex }\end{array}$ \\
\hline Glick et $a l^{33}$ & $\begin{array}{l}\text { Compared twice weekly, weekly and biweekly diaries with } 3 \text { month retrospective survey } \\
\text { Non-significant under-reporting on retrospective survey } \\
\text { Most concordance correlation coefficient and } \kappa \text { statistics } \geq 80 \%\end{array}$ \\
\hline Horvath et $a l^{37}$ & $\begin{array}{l}\text { Compared daily diary with retrospective survey } \\
\text { Over-reported receptive oral and anal sex on survey (all } p<0.05) \\
\text { Greater frequency of giving oral sex }(p<0.05) \text {, receiving oral sex }(p<0.01) \text {, and higher number of sexual events }(p<0.01) \text { were } \\
\text { associated with over-reporting on survey } \\
\text { Greater frequency of unprotected insertive anal sex was associated with under-reporting on survey }(p<0.001) \\
28-85 \% \text { of participants over-reported or under-reported each behaviour on the retrospective survey }\end{array}$ \\
\hline Lim et $a l^{2}$ & $\begin{array}{l}\text { Compared online, text-message and paper weekly diaries with retrospective survey } \\
\text { Correlation was high for proportion of partners considered 'regular' (0.87), frequency of sex (0.76), frequency of condom use } \\
(0.76) \text { and STI risk }(0.74) \\
\text { - Correlation was lower for number of partners }(0.63) \text { and proportion of partners considered 'new' }(0.57)\end{array}$ \\
\hline \multicolumn{2}{|r|}{ ( } \\
\hline Glick et $a \beta^{33}$ & $\begin{array}{l}\text { Compared recall from active diary participants with controls } \\
\text { Controls had } 0.9 \text { more new male partners than diary subjects }(p=0.05) \\
\text { Controls had significantly greater increases in frequency of anal } \operatorname{sex}(p=0.01) \text {, frequency of unprotected anal sex }(p<0.01) \text { and any } \\
\text { unprotected anal sex }(p<0.01) \\
\text { Controls had significantly higher STI and HIV diagnosis incidence rates }(26.1 \%) \text { than active diary participants }(4.8 \%, p=0.01) \\
\text { No evidence of dose-response by diary frequency } \\
\text { Author explanation: difference in HIV/STI incidence indicates that risky behaviour may have actually differed over time between } \\
\text { groups; attributed to diaries because of controlled nature of study }\end{array}$ \\
\hline Hensel et $a l^{3}$ & $\begin{array}{l}\text { Diary completion fell significantly over time }(-0.61 \% / \text { week, } p<0.05) \\
\text { Reports of vaginal sex decreased significantly over time }(-0.61 \% / \text { week, } p<0.05) \\
\text { Greater decrease in vaginal sex was reported in } 18-20 \text {-year-olds }(-0.91 \% / \text { week), } 27-29 \text { year-olds }(-0.83 \% / \text { week }) \text {, men }(-0.80 \% \text { / } \\
\text { week) and patients without STI at enrolment }(-0.68 \% / \text { week) (all } p<0.05) \\
\text { Author explanation: slight differences in reported behaviour during study may be due to subtle changes in behaviour over time, } \\
\text { not diary participation }\end{array}$ \\
\hline Horvath et al ${ }^{37}$ & $\begin{array}{l}\text { Statistically significant decline in giving oral sex, receiving oral sex, insertive anal sex and unprotected receptive anal sex over time } \\
\text { (all } p<0.05 \text { ) } \\
\text { Author explanation: diary completion leads to self-monitoring, which causes participants to reduce risky behaviours over time }\end{array}$ \\
\hline Kiene et $a l$, Kiene et al ${ }^{\beta 8} 39$ & - No evidence of reactivity \\
\hline $\begin{array}{l}\text { Newcomb, Newcomb and } \\
\text { Mustanski }\end{array}$ & - No evidence of reactivity \\
\hline
\end{tabular}

*Over-reporting and under-reporting on retrospective surveys compared with diaries.

sex were almost universally measured, as partner-specific and aggregate variables. Overall, correlation between diary and retrospective data was high, indicating that both methods likely provide valid estimates. However, accuracy tended to be greater for less frequent behaviours, and over-reporting on retrospective surveys exceeded under-reporting. Clearly, study aims and data needs should be considered when selecting a data collection tool. This appears to be especially true for high-frequency behaviours (eg, number of sex acts) where diary data likely provide more accurate count data.

It is difficult to draw firm conclusions about reactivity in webbased sexual risk behaviour diaries given the paucity of quality studies. The notion that 'self-monitoring' can generate behaviour change has been studied within the context of many health behaviours-notably in exercise and weight loss intervention research-although the findings of controlled studies have overall been equivocal. Nevertheless, among those studies evaluating the effect of diaries (web-based and non-web-based) on sexual behaviours, diary completion has been consistently associated with lower rates of sexual risk behaviour. ${ }^{33}$ 52-54
Although further controlled research with more diverse populations is needed to confirm these findings, available data suggest that researchers using diaries should consider that this methodology may, in fact, be an intervention itself.

This review has two main limitations. First, we could not assess the presence of publication bias, but it is possible that web-based diary studies with non-significant findings or inadequate completion were less likely to be published. Second, the broad parameters used to identify articles minimised the risk of missing eligible records, but it is still possible that our strategy did not identify all relevant articles.

Our review highlights several areas for future research on web-based diaries specific to sexual risk behaviour. Research should identify subjects' preferred diary mediums, frequency and length, and use diaries with populations beyond MSM and university students. Cellphone diaries possess largely unexplored potential, as apps for smartphones can collect data, transmit to study staff and enable staff to remind participants to complete diaries. This medium is particularly compelling for research and prevention efforts among traditionally hard-to-reach 
populations, as demonstrated in one study of low-income STI clinic attendees. ${ }^{3}$ In addition, phone-based diaries may be especially effective among young black MSM-a priority population for HIV/STI prevention research in the USA - given that smartphone use appears to be extremely common and accepted as an intervention tool. ${ }^{55}$ Studies should also examine methods, including compensation, that maximise completion. Reactivity studies should incorporate control groups to avoid conflating temporal trends with behavioural reactivity. These studies could also identify features that affect reactivity, such as frequency, length of collection or medium. Long-term studies should examine if reactivity is temporary or long-lasting. Finally, there is limited information on how missing diary data are handled analytically. Future research should examine if diary entries are missing at random, which would inform the use of imputation.

Web-based diaries provide many benefits, including remote data collection and reduced data entry burden. However, the potentially substantial costs of software, hardware and privacy requirements associated with implementing a web-based methodology indicate that researchers should consider their data needs and population when selecting a web-based diary. 125657 This tool is a promising technological advancement for HIV/STI research, and future studies should continue to employ rigorous study designs to clarify the most appropriate methodological practices.

Key messages

- To date, most web-based, quantitative, sexual risk behaviour diaries have been daily, month-long studies collected using websites.

- Methods that maximise diary completion are unclear, partially due to non-systematic reporting of completion rates.

- Compared with diaries, retrospective surveys appear to collect valid measures of sexual risk behaviour, but may overestimate the frequency of more common behaviours.

- Reactivity due to diary completion may decrease sexual risk behaviour, but additional controlled studies are needed.

\section{Handling editor Jackie A Cassell}

Contributors SNG developed the review idea. CS conducted literature searches and preliminary screening. SNG and CS completed full-text reviews and data extraction for final articles. CS drafted the paper, with substantial input from SNG.

Funding SNG was supported by the District of Columbia Developmental Center for AIDS Research (P30 Al087714).

\section{Competing interests None.}

Provenance and peer review Not commissioned; externally peer reviewed.

\section{REFERENCES}

1 Bolger N, Davis A, Rafaeli E. Diary methods: capturing life as it is lived. Annu Rev Psychol 2003;54:579-616.

2 Lim MS, Sacks-Davis R, Aitken CK, et al. Randomised controlled trial of paper, online and SMS diaries for collecting sexual behaviour information from young people. J Epidemiol Community Heal 2010;64:885-9.

3 Hensel DJ, Fortenberry JD, Harezlak J, et al. The feasibility of cell phone based electronic diaries for STI/HIV research. BMC Med Res Methodol 2012;12:75.

4 Bavaro JB, Drolette L, Koelle DM, et al. One-day regimen of valacyclovir for treatment of recurrent genital herpes simplex virus 2 infection. Sex Transm Dis 2008:35:383-6.
5 Schroder KEE, Carey MP, Vanable PA. Methodological challenges in research on sexual risk behavior: I. Item content, scaling, and data analytical options. Ann Behav Med 2003;26:76-103.

6 Leigh BC, Stall R. Substance use and risky sexual behavior for exposure to HIV: issues in methodology, interpretation, and prevention. Am Psychol 1993;48:1035-45.

7 Stone AA, Shiffman S, Schwartz JE, et al. Patient compliance with paper and electronic diaries. Control Clin Trials 2003:24:182-99.

8 Stone AA, Shiffman S, Schwartz JE, et al. Patient non-compliance with paper diaries. BMJ 2002;324:1193-4.

9 Broderick JE, Schwartz JE, Shiffman S, et al. Signaling does not adequately improve diary compliance. Ann Behav Med 2003;26:139-48

10 Green AS, Rafaeli E, Bolger N, et al. Paper or plastic? Data equivalence in paper and electronic diaries. Psychol Methods 2006;11:87-105.

11 Barrett LF, Barrett DJ. An introduction to computerized experience sampling in psychology. Soc Sci Comp Rev 2001;19:175-85.

12 Courtney KL, Craven CK. Factors to weigh when considering electronic data collection. Can J Nurs Res 2005;37:150-9.

13 Catania JA, Binson D, van der Straten A, et al. Methodological research on sexual behavior in the AIDS era. Annu Rev Sex Res 1995:6:77-125.

14 Graham CA, Catania JA, Brand R, et al. Recalling sexual behavior: a methodological analysis of memory recall bias via interview using the diary as the gold standard. J Sex Res 2003;40:325-32.

15 Weinhardt LS, Forsyth AD, Carey MP, et al. Reliability and validity of self-report measures of HIV-related sexual behavior: progress since 1990 and recommendations for research and practice. Arch Sex Behav 1998:27:155-80.

16 Newcomb ME, Mustanski B. Diaries for observation or intervention of health behaviors: factors that predict reactivity in a sexual diary study of men who have sex with men. Ann Behav Med Published Online First: 1 Oct 2013. doi:10.1007/ s12160-013-9549-8

17 Crosby RA, Charnigo RA, Weathers C, et al. Condom effectiveness against non-viral sexually transmitted infections: a prospective study using electronic daily diaries. Sex Transm Infect 2012:88:484-9.

18 Shrier LA, Koren S, Aneja P, et al. Affect regulation, social context, and sexual intercourse in adolescents. Arch Sex Behav 2010;39:695-705.

19 Vannier SA, O'Sullivan LF. The feasibility and acceptability of handheld computers in a prospective diary study of adolescent sexual behaviour. Can J Hum Sex 2008;17:183-92.

20 Vasilenko SA, Lefkowitz ES, Maggs JL. Short-term positive and negative consequences of sex based on daily reports among college students. J Sex Res 2012;49:558-69.

21 Ridley C, Ogolsky B, Payne $P$, et al. Sexual expression: its emotional context in heterosexual, gay, and lesbian couples. J Sex Res 2008;45:305-14.

22 Roney JR, Simmons ZL. Hormonal predictors of sexual motivation in natural menstrual cycles. Horm Behav 2013;63:636-45.

23 Reece M, Mark K, Herbenick D, et al. An event-level analysis of adding exogenous lubricant to condoms in a sample of men who have vaginal sex with women. J Sex Med 2012;9:672-8.

24 Herbenick D, Hensel D, Smith NK, et al. Pubic hair removal and sexual behavior: findings from a prospective daily diary study of sexually active women in the United States. J Sex Med 2013;10:678-85.

25 Herbenick D, Reece M, Hensel D, et al. Association of lubricant use with women's sexual pleasure, sexual satisfaction, and genital symptoms: a prospective daily diary study. J Sex Med 2011;8:202-12.

26 Jozkowski KN, Herbenick D, Schick V, et al. Women's perceptions about lubricant use and vaginal wetness during sexual activities. J Sex Med 2013;10:484-92.

27 Hensel DJ, Stupiansky NW, Herbenick D, et al. Sexual pleasure during condom-protected vaginal sex among heterosexual men. J Sex Med 2012:9:1272-6

28 Diamond LM, Wallen K. Sexual minority women's sexual motivation around the time of ovulation. Arch Sex Behav 2011;40:237-46.

29 Baer A, Saroiu S, Koutsky LA. Obtaining sensitive data through the Web: an example of design and methods. Epidemiology 2002;13:640-5.

30 Boone MR, Cook SH, Wilson P. Substance use and sexual risk behavior in HIV-positive men who have sex with men: an episode-level analysis. AIDS Behav 2013;17:1883-7.

31 Edelstein ZR, Schwartz SM, Hawes S, et al. Rates and determinants of oral human papillomavirus infection in young men. Sex Transm Dis 2012;39:860-7.

32 Garry M, Sharman SJ, Feldman J, et al. Examining memory for heterosexual college students' sexual experiences using an electronic mail diary. Heal Psychol 2002;21:629-34.

33 Glick SN, Winer RL, Golden MR. Web-based sex diaries and young adult men who have sex with men: assessing feasibility, reactivity, and data agreement. Arch Sex Behav 2013:42:1327-35.

34 Grov C, Golub SA, Mustanski B, et al. Sexual compulsivity, state affect, and sexual risk behavior in a daily diary study of gay and bisexual men. Psychol Addict Behav 2010;24:487-97

35 Hensel DJ, Rosenberger JG, Novak DS, et al. Sexual event-level characteristics of condom use during anal intercourse among HIV-negative men who have sex with men. Sex Transm Dis 2012;39:550-5. 
36 Hensel DJ, Stupiansky NW, Herbenick D, et al. When condom use is not condom use: an event-level analysis of condom use behaviors during vaginal intercourse. J Sex Med 2011;8:28-34.

37 Horvath KJ, Beadnell B, Bowen AM. A daily web diary of the sexual experiences of men who have sex with men: comparisons with a retrospective recall survey. AIDS Behav 2007; 11:537-48.

38 Kiene SM, Barta WD, Tennen $\mathrm{H}$, et al. Alcohol, helping young adults to have unprotected sex with casual partners: findings from a daily diary study of alcohol use and sexual behavior. J Adolesc Heal 2009;44:73-80.

39 Kiene SM, Tennen H, Armeli S. Today I'll use a condom, but who knows about tomorrow: a daily process study of variability in predictors of condom use. Heal Psychol 2008;27:463-72.

40 Mustanski B. Moderating effects of age on the alcohol and sexual risk taking association: an online daily diary study of men who have sex with men. AIDS Behav 2008;12:118-26.

41 Mustanski B. The influence of state and trait affect on HIV risk behaviors: a daily diary study of MSM. Heal Psychol 2007;26:618-26.

42 Mustanski BS. Are sexual partners met online associated with HIV/STI risk behaviours? Retrospective and daily diary data in conflict. AIDS Care 2007;19:822-7.

43 Newcomb ME. Moderating effect of age on the association between alcohol use and sexual risk in MSM: evidence for elevated risk among younger MSM. AIDS Behav 2013;17:1746-54.

44 Newcomb ME, Mustanski B. Racial differences in same-race partnering and the effects of sexual partnership characteristics on HIV risk in MSM: A prospective sexual diary study. J Acquir Immune Defic Syndr 2013;62:329-33.

45 Partridge JM, Hughes JP, Feng Q, et al. Genital human papillomavirus infection in men: incidence and risk factors in a cohort of university students. J Infect Dis 2007; 196:1128-36.
46 Reece M, Herbenick D, Sanders SA, et al. Breakage, slippage and acceptability outcomes of a condom fitted to penile dimensions. Sex Transm Infect 2008:84:143-9.

47 Strachman A, Impett EA. Attachment orientations and daily condom use in dating relationships. J Sex Res 2009:46:319-29.

48 Wilson PA, Cook S, McGaskey J, et al. Situational predictors of sexual risk episodes among men with HIV who have sex with men. Sex Transm Infect 2008;84:506-8.

49 Winer RL, Hughes JP, Feng Q, et al. Condom use and the risk of genital Human Papillomavirus infection in young women. N Engl J Med 2006;354:2645-54.

50 Harel O, Pellowski J, Kalichman S. Are we missing the importance of missing values in HIV prevention randomized clinical trials? Review and recommendations. AIDS Behav 2012;16:1382-93.

51 Stone AA, Shiffman S. Capturing momentary, self-report data: a proposal for reporting guidelines. Ann Behav Med 2002;24:236-43.

52 Lightfoot M, Rotheram-Borus MJ, Comulada S, et al. Self-monitoring of behaviour as a risk reduction strategy for persons living with HIV. AIDS Care 2007;19:757-63.

53 Schroder KE, Johnson CJ, Wiebe JS. Interactive Voice Response Technology applied to sexual behavior self-reports: a comparison of three methods. AIDS Behav 2007;11:313-23.

54 Tucker JA, Blum ER, Xie L, et al. Interactive voice response self-monitoring to assess risk behaviors in rural substance users living with HIVIAIDS. AIDS Behav 2012;16:432-40.

55 Muessig KE, Pike EC, Fowler B, et al. Putting prevention in their pockets: developing mobile phone-based HIV interventions for black men who have sex with men. AIDS Patient Care STDs 2013:27:211-22.

56 Couper MP. Web surveys: a review of issues and approaches. Public Opin Q 2000;64:464-94.

57 Mustanski B. Getting wired: exploiting the Internet for the collection of valid sexuality data. J Sex Res 2001:38:292-301. 